\title{
Skills for business and management
}

\section{A book review of Sedgley, M. (2020) Skills for business and management. London: Red Globe Press.}

\author{
Anne Davey \\ Bournemouth University, UK
}

Keywords: Academic writing; business and management; critical analysis; group work; personal development planning; plagiarism; presentation skills; reading; referencing; reflective writing; time management.

\section{Overview}

The transition into university can be a stressful experience for many students. They are often faced with having to adapt to a very different way of learning, compared to their previous experiences of study. This book aims to help students embarking on a business and management course at university to overcome some of these hurdles. It concentrates on five key study skills needed by university students: time management, academic reading, academic writing, group work, and independent learning. There are a lot of general study skills books available, but this book is of particular interest as it concentrates on skills development for business management and finance students.

Martin Sedgley draws on his considerable experience of working in learning support to offer practical guidance and learning strategies to undergraduate and postgraduate students. His knowledge and obvious enthusiasm for the subject comes across very clearly in this useful and practical book.

\section{Structure and content}


The first chapter sets the scene for the rest of the book. It gives a brief overview of the topics covered. It offers some diagnostic tests to establish whether the reader understands the difference between their previous experience of study and studying in higher education. Advice is given on how to get the most out of the book. Each chapter starts with a list of intended learning outcomes and finishes with a summary of the topics covered. The emphasis is on active learning, therefore there are activities and quizzes in every chapter. This active learning approach is very effective and helps to lead the reader through the book. It also allows them to pause at different points to test their understanding of the subjects in each section. Throughout the whole book the author stresses the importance of developing transferrable skills thus enhancing the students' employability. He reinforces his points with quotes from business, management, accounting, and finance students. The quotes are a nice touch and help the reader relate to the issues being discussed.

The first main section of the book deals with time management and self-management. It begins with advice on managing challenging times while studying at university. This includes enhancing self-confidence, assessment success, dealing with emotional challenges, and the importance of reflection. Sedgley bases much of the advice in this chapter on the work of Albert Bandura, the psychologist who first came up with the term self-efficacy (Bandura, 1997). Lots of books have been written on time management but not many combine this skill with self-efficacy. This holistic approach to time management helps to make it more relevant to students who are facing major life changes when moving into higher education. The chapter on time management covers daily and weekly planning, managing perfectionism, and how to deal with procrastination. Various time management techniques are discussed including the Place Mat Process (Hicks and Hicks, 2004). This aims to align long term goals and aspirations with short term time management, thus returning to the author's holistic approach to study skills acquisition. There is a nice mix of well-known techniques and some more uncommon ones such as the Place Mat Process.

Next is a section on academic research. This includes chapters on searching for relevant texts and employing efficient reading strategies. The chapter on searching for relevant texts gives hints and tips on finding different types of sources such as textbooks, marketing reports, financial newspapers, and journals. It is gratifying and reassuring to see that students are advised to use library resources, rather than relying on Google, and to seek support from the 
business librarians at their institution. The author takes a sample essay title and then guides the reader through a series of exercises designed to help them refine their research skills. This is a very effective way of bringing together different aspects of the research process. Different ways of improving reading skills are discussed, including selective reading, scanning, and reading for notetaking.

Academic writing is discussed next. This section covers academic writing, referencing, critical analysis, and reflective writing. Many students struggle with academic writing and critical thinking. This book offers practical help in this area. The chapters in this section have a clear structure and offer a range of activities and quizzes. These are very helpful in guiding the reader through the process of academic writing and critical analysis, in a logical and straightforward way. Each one builds on the previous activity. This approach works very well. The result is a useful and practical guide for students on how to develop their own individual writing style or voice. The final chapter in the section looks at reflective writing and its importance in long term professional development. Most of the exercises are based around Gibbs' Reflective Cycle (Gibbs, 1988). The use of sample essays as part of the activities, to demonstrate good writing practice, is a particularly nice touch.

The fourth section of the book focusses on communication and contains chapters on group work and delivering effective presentations. The author introduces these soft skills by explaining why being able to work in teams and communicating effectively is so important in the workplace. One of the nice things about this book is the way that Sedgley underpins the study skills discussed with the need to develop transferable skills and therefore become more employable. Different team building methods are discussed, including analysis of personality traits and how to exploit them effectively. The Myers-Briggs system is used as an example in many of the activities.

The final section deals with personal development planning. It encourages the reader to make the most of their learning journey and to come up with an action plan for their future professional development. This section neatly brings together the different strands running through the book dealing with reflection, self-efficacy, and professional development. Readers are encouraged to carry out their own personal SWOT analysis. This is similar to the strengths, weaknesses, opportunity, and threat analysis familiar to all business management 
students, with two important differences. Weaknesses are replaced with worries and threats become tendencies. By doing this, the author has very cleverly and effectively taken what could have been a rather negative exercise, stressing weaknesses and threats, and turned it into a positive affirmation of skills and attributes.

\section{Summary}

This book is primarily aimed at students starting a degree course. However, students of all levels would find it useful for improving their study skills. The practical and interactive nature of the book makes it ideal for students to use in independent study. It would work with a range of learning styles, particularly visual and kinesthetic learners. In addition, some of the activities could be used by librarians, learning developers, and study skills tutors as a starting point to develop their own workshops and face-to-face interactions with students.

\section{References}

Bandura, A. (1997) Self-efficacy: the exercise of control. New York: Freeman.

Gibbs, G. (1988) Learning by doing: a guide to teaching and learning methods. Oxford: Further Education Unit, Oxford Polytechnic.

Hicks, E. and Hicks, J. (2004) Ask and it is given: learning to manifest your desires. London: Hay House.

\section{Author details}

Anne Davey is a Faculty Librarian at Bournemouth University, supporting staff and students in the Bournemouth University Business School. She also manages the university's library and learning support study skills provision. Anne has been working in academic libraries for over 
30 years. Research interests include transitions into higher education, the development of transferrable skills, and student employability. 